\title{
Effect of Zero Air Change Rate On Particle Dispersion in A Room with Floor Heating
}

\author{
Mustafa Mutlu* \\ Uludag University, Vocational School of Yenisehir Ibrahim Orhan, 16900, Bursa, Turkey
}

\begin{abstract}
Dispersion of airborne particles in the office and residential areas should be well known as these particles in an enclosed volume has a significant effect on human health. In this study, the effect of the floor heating system, which is often preferred by end users due to the energy efficiency of low heating systems, on particle distribution in a room was investigated numerically. It is essential to examine the floor heating having a significant place among low heating systems, concerning particle dispersion. In enclose volumes, ambient air should be replaced with fresh air that is supplied from outdoor in order to ensure indoor air quality. However, the ideal air change rates may not be met for daily use, even in some cases air change rates might be zero. Therefore, in this study absence of air change were assumed, and after temperature and velocity distributions were determined, five different sized particles were tracked by using EulerianLagrangian model. Additionally, three heating capacities $\left(35 \mathrm{~W} / \mathrm{m}^{2} 41.25 \mathrm{~W} / \mathrm{m}^{2}\right.$ and $\left.47 \mathrm{~W} / \mathrm{m}^{2}\right)$ of the floor heating system were investigated. In this study, where computational fluid dynamics were used, the effect of drag, lift, thermophoretic and Brownian forces were considered. It was found that particles were settled on walls and ceiling due to zero air change rate, and particle concentration rises in the lower part of the wall as particle diameter increases.
\end{abstract}

\section{Introduction}

Heating systems used in buildings are designed for supplying desired thermal conditions in our living areas. Providing thermal comfort is playing an important role in terms of life quality and energy efficiency, but distribution and behavior of particles, located in conditioned space is ignored during design phase of heating system. Particles, whose diameter is $10 \mu \mathrm{m}$ or less, are respirable and can cause deadly diseases according to World Health Organization [1]. One of the substantial factor that influence the distribution of these particles is air conditioning units used in houses and offices, particularly heating systems are significantly affect the particle distribution in room ambient.

Air temperature and velocity distribution in living spaces were investigated both numerically and experimentally by many researchers [2 - 8]. Today efficient heating systems are becoming widespread as energy consumption takes an important place in human preferences. One of these system is floor or wall heating called radiant heating systems $[9,10]$. Although particle behaviors in a space is introduced as the most critical disadvantages of floor heating systems, there are limited studies on this subject. Golkarfard and Talebizadeh were numerically compared floor and radiator heating systems in terms of particle distribution, whose diameter is between 3 and $10 \mu \mathrm{m}$, in a room [11]. They found that, particle concentration in radiator heating was found higher than floor heating system for all investigated * Corresponding author: mustafamutlu@uludag.edu.tr particle diameters. It is determined that, deposition places of particles were varied by heating system type. It was observed that, particles were accumulated on ceiling for floor heating system and on floor for radiator heating system. They concluded that, other than expected, particle concentration is higher in radiator heating system, because of particle circulation occurred in the room. Gagyte et al. specified the effect of floor and air heating systems that combined with a mixing ventilation, on exposure levels of humans to respirable contaminants [12]. They pointed out that, heating system had no effect on ventilation effectiveness, while contaminant concentration was $\% 31$ less in floor heating system. In a similar study done by Jurelionis et al., it was seen that, contaminant concentration increased in case of using combined air heating, and this situation cannot be solved by improving air change rates [13]. In another research that the effect of floor heating system was examined it was seen that, removal effectiveness of floor source contaminants was improved, where it reduced the respirable contaminant concentration [14]. Zhou et al. investigated the deposition of $1 \mu \mathrm{m}$ sized particles for various inlet velocities and surface temperatures, and they showed that, accumulated rate of particles on floor decreased as inlet velocity and surface temperature increased. They concluded that, removal time of particles can be reduced $15 \%$ by increasing floor temperature [15]. Dehghan and Abdolzadeh examined particle concentration, formed by three different heating systems, around a mannequin using CFD method [16]. It is seen 
that, maximum particle concentration values near breathing zone of the mannequin was obtained in radiator heating system while minimum concentration values were in skirting boarding heating system.

In researches, which effect of heating systems on particle distribution in an office or a house were studied, air change rates has been assumed that it occurred as in standards. However, it is hard to ensure recommended air change values in real life, and end users disregard this values. Therefore, distribution of different sized particles in a room, in which air change rate were assumed to be zero, were analyzed in this study by numerically, and effect of heat flux were introduced.

\section{Numerical model and boundary conditions}

The dimensions of geometrical model of the room was created based on experimental studies carried out by Olesen et al [2]. Results of this study, that referenced by other researchers as well [16-20], is a valuable resource to compare numerical data with experiments. The room dimensions used in analysis was taken as $4.8 \mathrm{~m} \times 2.4 \mathrm{~m} \times$ $2.7 \mathrm{~m}$ and its schematic view was given in Figure 1 .

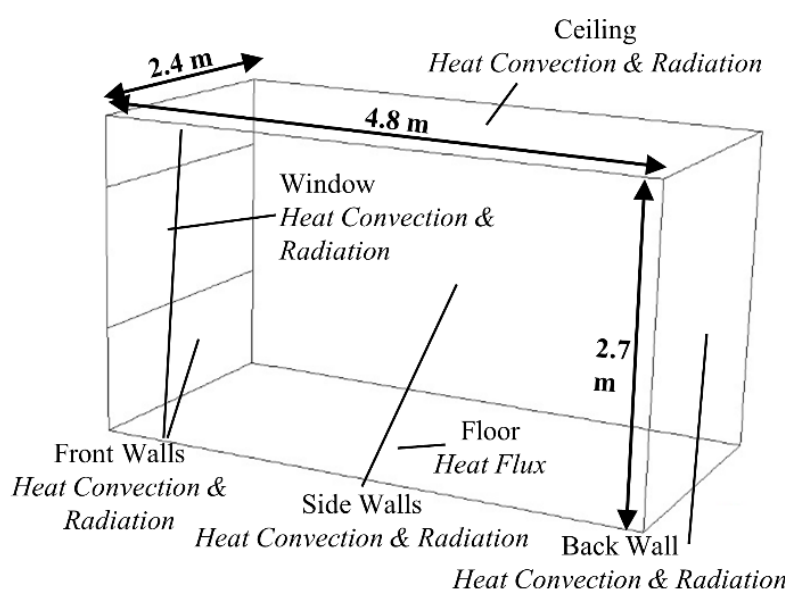

Fig. 1. Schematic of the room and boundary conditions

Three dimensional Navier-Stokes and energy equations, where gravitational forces were taken into account, had been solved by a commercial software FLUENT under steady state conditions. Air properties, except density which is modelled as incompressible ideal gas, were assumed to be constant and given in Table 1. Low-Re k- $\varepsilon$ turbulence model which is preferred at low velocities and used in other studies, were applied and S2S radiation model were chosen for radiation calculations inside the room.

Table 1. Properties of air

\begin{tabular}{|l|l|}
\hline Specific Heat & $1006.43 \mathrm{~J} / \mathrm{kgK}$ \\
\hline Thermal Conductivity & $0.0242 \mathrm{~W} / \mathrm{mK}$ \\
\hline Viscosity & $1.7894 \times 10^{-5} \mathrm{~kg} / \mathrm{ms}$ \\
\hline Molecular Weight & $28.966 \mathrm{~kg} / \mathrm{kmol}$ \\
\hline
\end{tabular}

Total heat transfer coefficients of room walls were taken from values determined by Olesen et al. [2], while internal heat transfer coefficients and radiation heat transfer rates were calculated by CFD software. Heat transfer coefficients over outer walls were assumed to be $7 \mathrm{~W} / \mathrm{m}^{2} \mathrm{~K}$. Dehghan and Abdolzadeh [16] calculated outer heat transfer coefficient over the same geometry and they found that despite existence of minor differences on various surfaces, the average heat transfer coefficient was around $7 \mathrm{~W} / \mathrm{m}^{2} \mathrm{~K}$. Mixed boundary condition was applied to the walls, where radiation heat transfer occurring between wall surfaces and outdoor air were considered and emissivity of the surfaces were taken as 0.9 . Heat input of floor heating system were modelled as constant heat flux because heating in experiments of referenced study [2] were supplied by electrical resistance wires. Heat flux value was calculated as $41.5 \mathrm{~W} / \mathrm{m}^{2}$ by using total heat transfer coefficients mentioned above, where indoor and outdoor air temperature was assumed to be 296 $\mathrm{K}$ and $268 \mathrm{~K}$ respectively. Three different heat fluxes (35 $\mathrm{W} / \mathrm{m}^{2}, 41.25 \mathrm{~W} / \mathrm{m}^{2}$ and $47 \mathrm{~W} / \mathrm{m}^{2}$ ) were applied to investigate the effect of the thermal capacity of the heating system. SIMPLEC and PISO algorithms were used for pressure velocity coupling and pressure discretization respectively. Better results have been achieved by selecting these methods. Second order discretization method was applied for momentum, turbulence and energy. Convergence criteria was chosen as $10^{-4}$ for continuity, momentum and turbulence, $10^{-6}$ for energy.

\section{Validation}

Obtained results were compared with experimental data in the literature [2] to validate of numerical data. In order to ensure mesh independence, results obtained from five different tetrahedral cell type mesh having different element number were compared. As shown in Figure 2 which represents comparison of numerical results with experimental data for different element numbers, no significant change has been seen mesh sizes whose element number was more than $2 \times 10^{6}$. Thus, the $2 \times 10^{6}$ sized mesh were selected to run analysis.

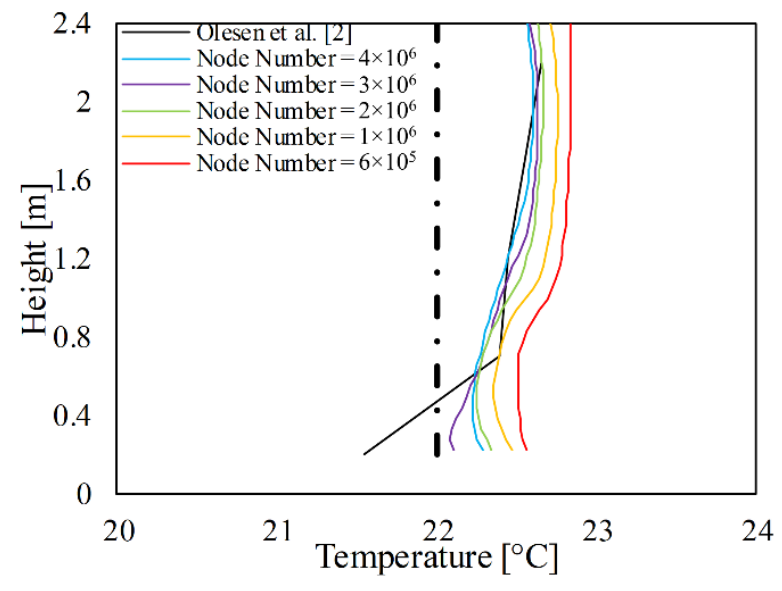

Fig. 2. Comparison of numerical results with the literature

When temperature results were evaluated it can be seen that, calculated temperature values were very close to experimental data. Calculated velocity values are 
similar to experimental data like temperature, such that measured velocities above $0.1 \mathrm{~m}$ floor level was $13 \mathrm{~cm} / \mathrm{s}$ and $14 \mathrm{~cm} / \mathrm{s}$ where calculated values were $14 \mathrm{~cm} / \mathrm{s}$ and 17 $\mathrm{cm} / \mathrm{s}$.

\section{Particle distribution}

In this study, it is assumed that lifting, drag, thermophoretic and Brownian forces influenced the particle movement in analysis. Force balance on a particle can be expressed by Eq. (1).

$$
\frac{d u_{p}}{d t}=F_{D}\left(u-u_{p}\right)+\frac{g\left(\rho_{p}-\rho\right)}{\rho_{p}}+F_{x}
$$

In this equation, $u$ is fluid velocity, $u_{p}$ particle velocity, $\rho$ is fluid density, $\rho_{p}$ is particle density, $F_{D}\left(u-u_{p}\right)$ is drag force per unit particle, $g$ is gravitational acceleration and $F_{x}$ is additional forces applied on particle term. In this study, drag force $\left(F_{D}\right)$ was calculated by using Stokes drag law [21], as follows:

$$
F_{D}=\frac{18 \mu}{d_{p}^{2} \rho_{p} C_{c}}
$$

Where $C_{c}$ is Cunningham correction factor and $\lambda$ represents the molecular mean free path can be calculated as:

$$
C_{c}=1+\frac{2 \lambda}{d_{p}}\left(1.257+0.4 e^{-\left(1.1 d_{p} / 2 \lambda\right)}\right)
$$

Termophoretic forces acting on particles were calculated by Eq. (4) that suggested by Talbot [22]:

$$
F_{x}=-\frac{6 \pi d_{p} \mu^{2} C_{s}\left(K+C_{t} K n\right)}{\rho\left(1+3 C_{m} K n\right)\left(1+2 K+2 C_{t} K n\right)} \frac{1}{m_{p} T} \frac{\partial T}{\partial x}
$$

Here, $K$ is ratio of fluid conductivity to particle conductivity $\left(k / k_{p}\right), m_{p}$ is particle mass, $T$ is fluid temperature and $\mu$ is fluid viscosity. $C_{s}, C_{t}$ and $C_{m}$ coefficients were taken as 1.17, 2.18 and 1.14, respectively, and Brownian force were calculated by following equation [23]:

$$
F_{b}=\zeta \sqrt{\frac{216 v k_{B} T}{\pi \rho d_{p}^{5}\left(\frac{\rho_{p}}{\rho}\right)^{2} C_{c} \Delta t}}
$$

where $\zeta$ is zero-mean independent Gaussian random numbers, $v$ is kinematic viscosity and $k_{B}$ is Boltzmann constant. Staffman lift force due to shear was calculated by Eq. (6) where $K$ is 2.594 and $d_{i j}$ is deformation tensor.

$$
F=\frac{2 K v^{1 / 2} \rho d_{i j}}{\rho_{p} d_{p}\left(d_{l k} d_{k l}\right)^{1 / 4}}\left(u-u_{p}\right)
$$

Concentration of particles in a single cell was calculated as follows:

$$
C_{c e l l}=\frac{m_{p, a} \dot{m}_{p} t}{m_{p} V_{c}}
$$

where $m_{p, a}$ is average particle mass in a cell, $\dot{m}_{p}$ is total mass flow rate of particle and $V_{c}$ is volume of the cell. After the concentration for a single cell $\left(C_{\text {cell }}\right)$ calculated, average particle concentration $\left(C_{V}\right)$ in the room were determined by using volume weighted average (Eq. 8).

$$
C_{V}=\frac{1}{V} \sum C_{c e l l} V_{c}
$$

Cell concentrations were normalized by dividing initial volume average concentration in the room in order to compare the results and evaluate effect of particle size (Eq. 9).

$$
C^{*}=\frac{C_{\text {cell }}}{C_{V}}
$$

Three lines, whose locations are given in Figure 3, were specified in the room and normalized concentrations on these lines were investigated.

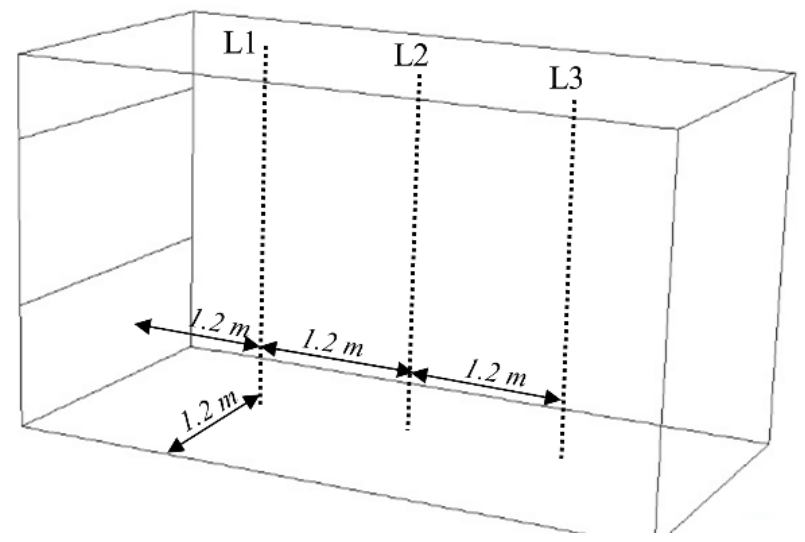

Fig. 3. Position of lines where particle normalized concentrations were investigated

\section{Results}

Air temperature and velocity distribution in a closed environment, where floor heating is applied, is under the influence of gravitational forces. Although, minor temperature deviation in the room is occurred, the near floor region is hotter than other places. However, it is seen that, a cold region is formed in the middle of the room due to effect of window's cold surface (Fig. 4). This cold region still exist in case of the heat flux is changed, but the temperature variation can be seen. Similarly, heat flux has no effect on temperature pattern on the floor, where floor surface near the window is colder, and the temperature rises as moving away from the window. The average floor temperature is $22.6^{\circ} \mathrm{C}, 27.4{ }^{\circ} \mathrm{C}$ and $31.9{ }^{\circ} \mathrm{C}$ while heat flux is $35 \mathrm{~W} / \mathrm{m}^{2}, 41.25 \mathrm{~W} / \mathrm{m}^{2}$ and $47 \mathrm{~W} / \mathrm{m}^{2}$ respectively. Therefore the room temperature is varied according to floor heating system capacity. 


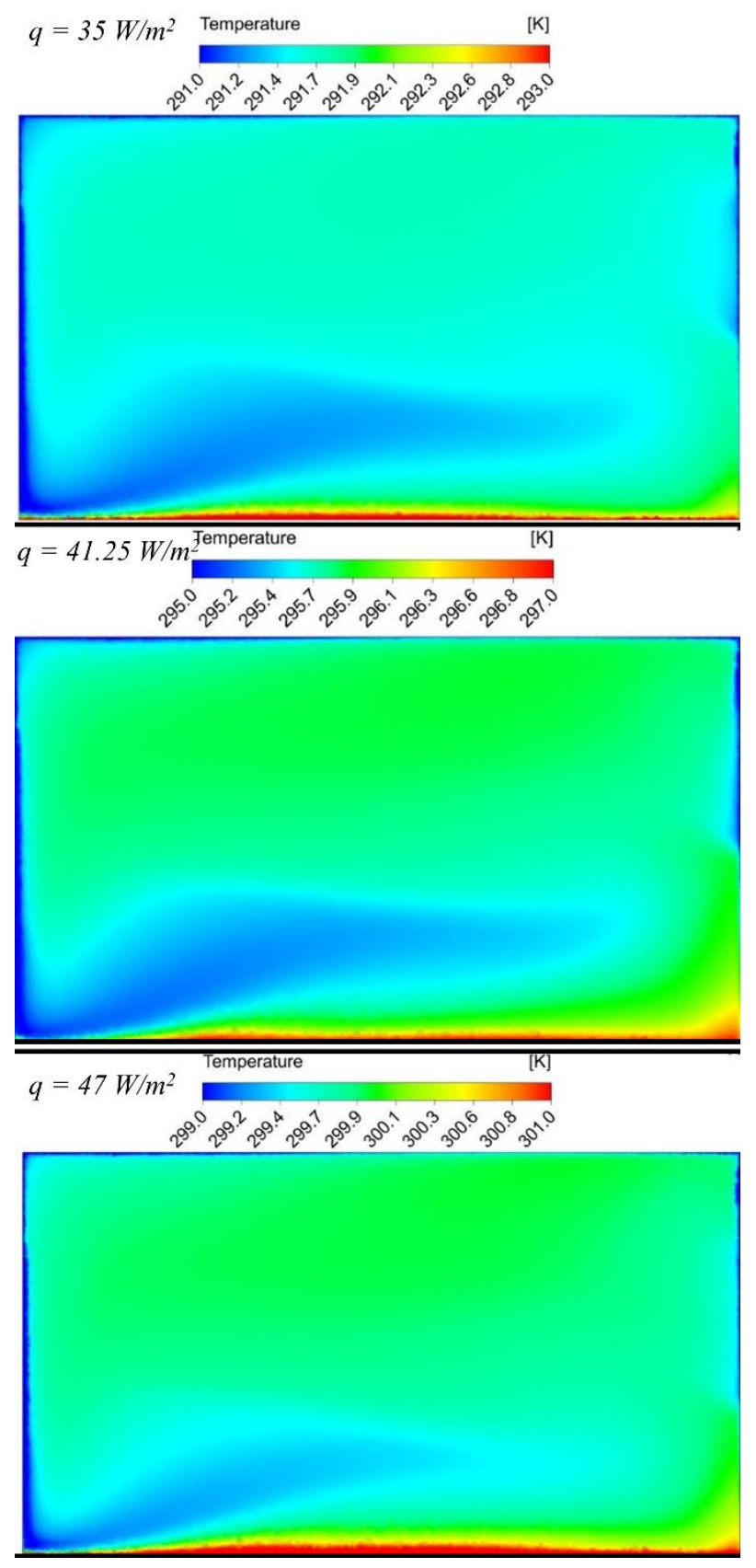

Fig. 4. Temperature distribution in the middle of the room

Air that contact with the cold surface of the window, moves towards the floor due to density changes. The air, just above the floor, moves upwards, because of warming due to contacting hot surface (Fig. 5). Air that cools down by contacting the window, moves towards the middle of the room as a result of interaction of these two different directional air flow, and cavity flow is formed nearly 1.2 $\mathrm{m}$ above the floor. Air velocities in this place of the room notably drops, and a critical zone is shaped in terms of particle distribution. Hot air that have contacted with the floor, moves towards the wall, then rises through the ceiling, and as a result of cooling its direction changes downwards. Similar research done by Myhren and Holmberg [17], that accepts that there is an air inlet through the window, showed that, air temperature close to the floor was colder than other regions and air velocities were higher than present study. Hence, it can be concluded that, air change rates considerably affect the flow and temperature characteristics in a room, as well as particle movements.
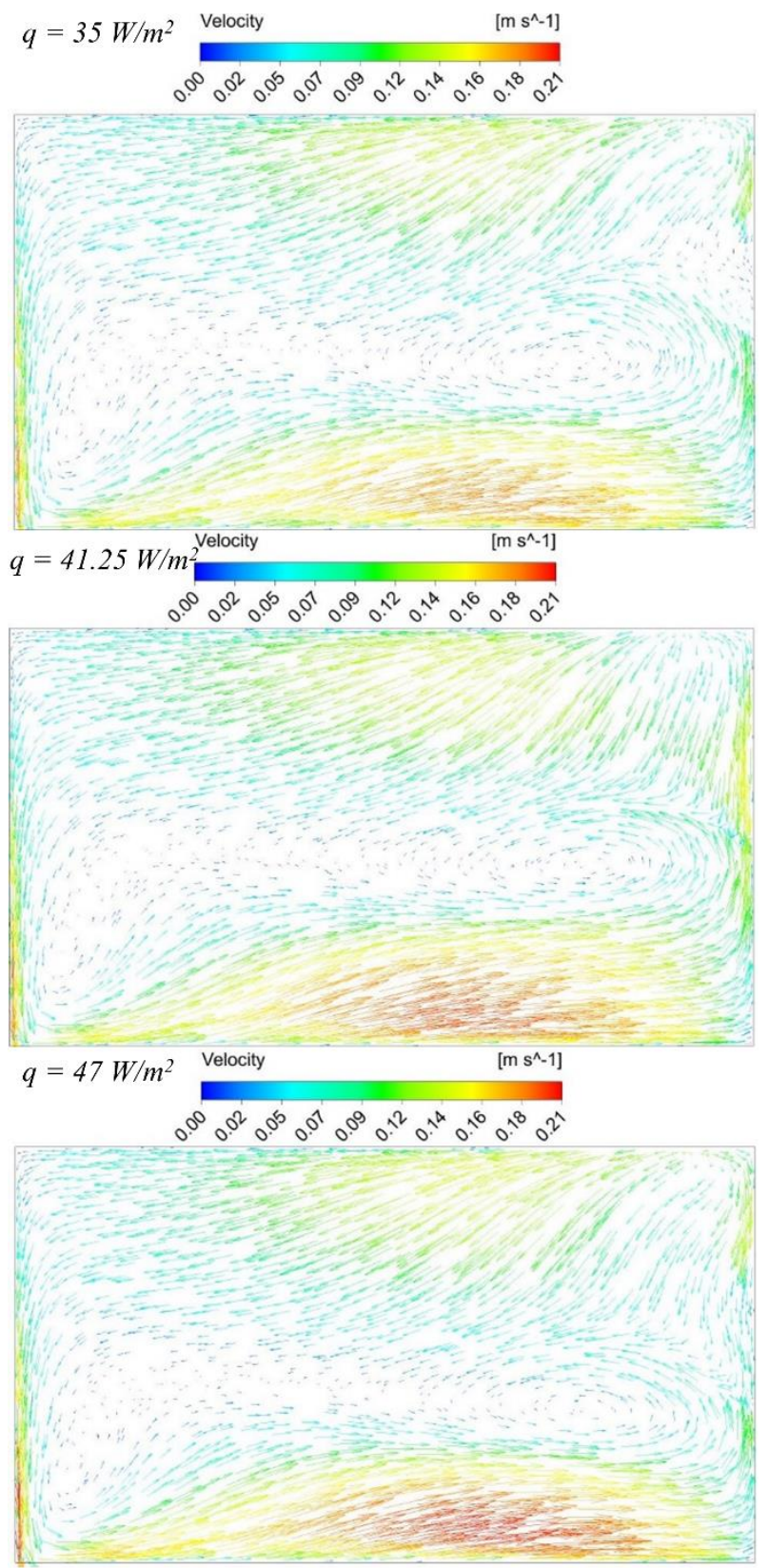

Fig. 5. Velocity vectors in the middle of the room

\section{Characteristics of particle distribution}

Although, movements and deposition of particles are highly related to velocity and temperature distribution in the environment, particle distribution is slightly influenced by heat flux. It can be concluded that particle concentration decreases as floor heating system power increases from Figure 6, which shows the volume average values of normalize particle concentration. Particle concentrations decrease, because the particles in the room adhered to walls. But the drop in concentration do not exceed $7.4 \%$ (Fig. 6a). It can be said that, as air velocity and temperature do not alter, concentration values are 
influenced by heating power, barely. On the other hand, the difference in concentration can be explained with temperature values that change with

different heating powers. Despite, particle size has minor effect on particle concentration, where it alters the concentration by $8.6 \%$, it can be said that, particle size is a more effective parameter than the heating power (Fig. $6 b)$.
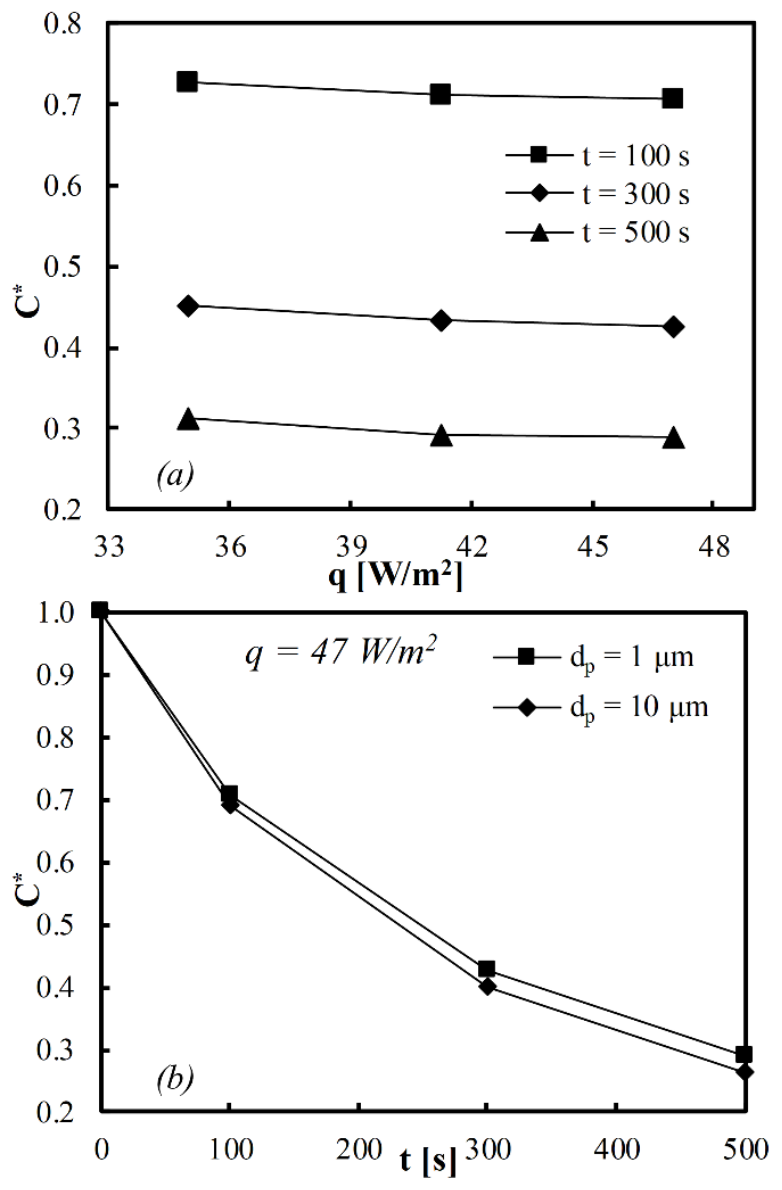

Fig. 6. Effect of heat flux (a) and particle diameters (b) on particle concentrations

Average concentrations are hardly affected by heating system parameters or particle sizes, as mentioned above, while concentration values can show different behavior in different locations of the room. Figure 7 shows the change of concentration values in different positions with room height. The maximum concentration is calculated on L1 line above $1 \mathrm{~m}$ from the floor for $47 \mathrm{~W} / \mathrm{m}^{2}$ heat flux. When the change of the concentration along the $\mathrm{Y}$ direction is examined, it can be concluded that there is a critical region where the particles are deposited. It can be said that this region is where the air velocity in the room decreases and the cavity flow occurs. Concentration values on L1 line 1 $\mathrm{m}$ above the floor is calculated higher than other locations after $300 \mathrm{~s}$ even the concentrations are decreases by time in all cases. When concentration values among positions are examined, it can be seen that, concentration on L3 position is slightly lower than other positions. Particle amount in the air decreases in this location of the room, because air shows an upward movement and flow over floor and wall surfaces, on where particles are trapped.
Despite the average concentration drops in entire room by increasing the heat flux, particle concentration rises on L1 and it decreases on L2 and L3 position. Particle concentration variation on L3 and L4 shows more stable state and enters the regime by time, while the particle concentration values have irregular behavior on L1. This irregular particle concentration on L1 position can be explained by interaction of cold air that flows over window and warm air that contact with the floor.

\section{Conclusion}

Particle distributions and behavior that affected by heating and cooling applications should be well known in terms of human health. Although air exchange rates are accepted according to standards when designing heating systems, end-users may not pay attention to this values. In this study, particle behavior was numerically investigated in a room where floor heating system was applied and air change rate is zero. Following conclusions can be made:

- A region with low air velocities and temperature is formed in the room independently from heating system power. Despite heating power has an effect on temperature values and air velocity magnitude, no important variation on air motion behavior has been observed.

- Particle distribution in the room is slightly affected by heating system power, and it is possible to decrease particle concentration up to $7.4 \%$ by increasing heat flux.

- It is found that, large sized particles are trapped on surfaces more than small sized particles. Consequently, concentration of particles with $10 \mu \mathrm{m}$ diameter calculated $8.6 \%$ lower than that of particles with $1 \mu \mathrm{m}$.

- It is seen that; maximum particle concentration is calculated at $1 \mathrm{~m}$ above the floor level due to cavity flow that occurs in the middle of the room. The particle concentration in the room can be reduced in places where people are heavily concentrated by managing this cavity flow within the volume. Hence, particles sources and velocity and temperature distributions formed by heating or cooling system should be well known.

This study is supported by Scientific and Technology Research Council of Turkey (TÜBİTAK), under project number 118M222. The Author thanks to the Scientific and Technology Research Council of Turkey. 

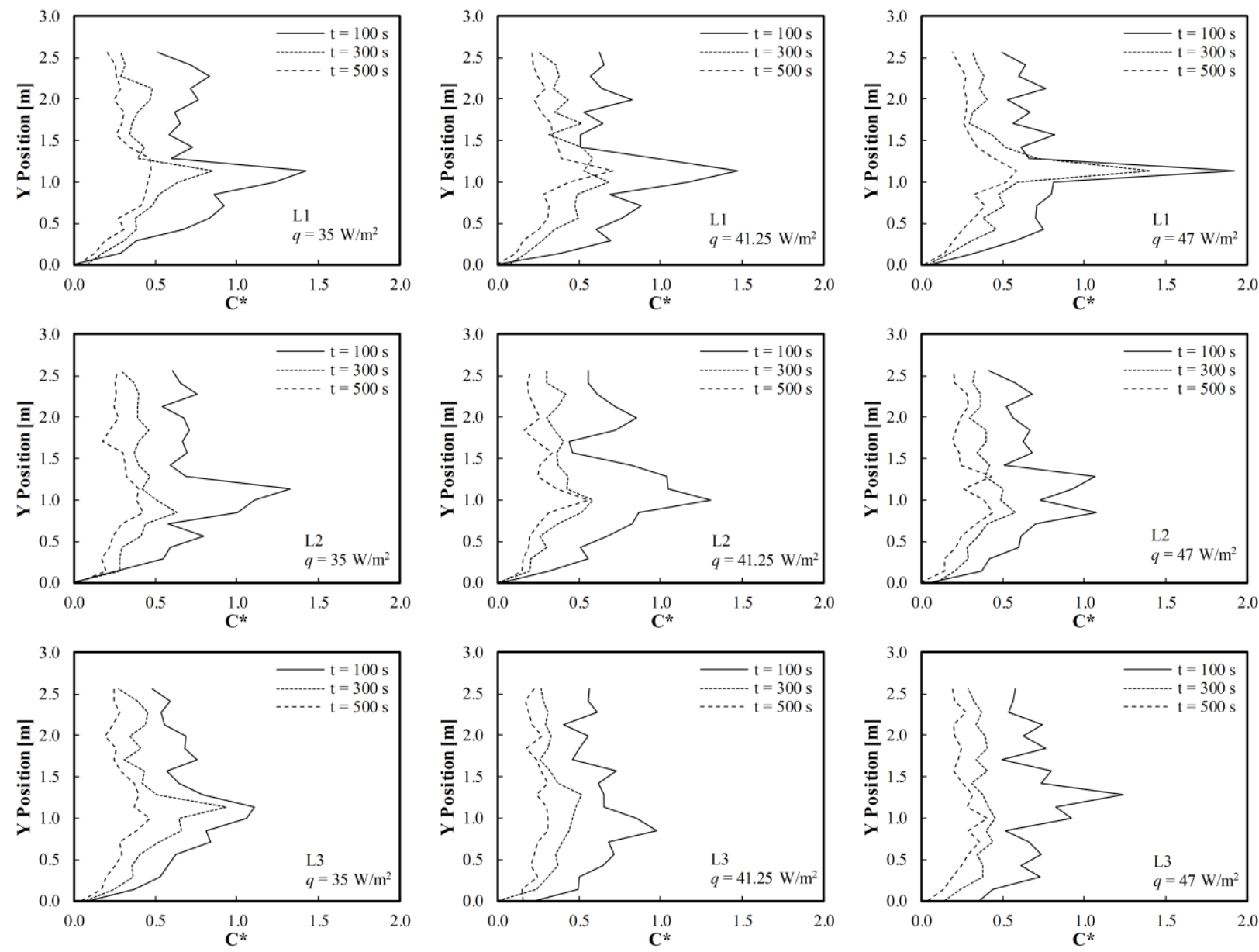

Fig. 7. Normalized particle concentrations on L1, L2 and L3

\section{References}

1. http://www.who.int/airpollution/household/pollutant s/combustion/en/ (Access Date: 19.09.2018)

2. B. W. Olesen, E. Mortensen, J. Thorshauge, B. BergMunch, ASHRAE Tran. 86, 34 (1980)

3. X. Wu, L. Fang, B. W. Olesen, J. Zhao, In Proceedings of the 8th international symposium on heating, ventilation and air conditioning, 59 (2014)

4. M. Abdolzadeh, M. S. Sargazizadeh, M. H. Dehghan, J Energ Eng 143(1) (2016)

5. T. Cholewa, A. Siuta-Olcha, M. A. Skwarczyński, Energ Buildings, 43(9), 2140-2144 (2011)

6. J. Léger, D. R. Rousse, K. Le Borgne, S. Lassue, Build Environ 128, 16 (2018)

7. O. B. Kazanci, M. Shukuya, B. W. Olesen, Build Environ, 99, 119 (2016)

8. M. Maivel, A. Ferrantelli, J. Kurnitski, Energy Build, 166, 220 (2018)

9. S. Sattari, B. Farhanieh, Renewable Energy, 31(10), 1617 (2006)

10. M. Bojić, D. Cvetković, V. Marjanović, M. Blagojević, Z. Djordjević, Energy Build, 61, 233 (2013)

11. V. Golkarfard, P. Talebizadeh, Adv Powder Technol, 25(1), 389 (2014)
12. L. Gagyte, A. Jurelionis, D. Martuzevicius, \& T. Prasauskas, 14th International Conference on Indoor Air Quality and Climate, (2016)

13. A. Jurelionis, L. Gagyte, L. Seduikyte, T. Prasauskas, D. Ciuzas, D. Martuzevicius, Energy Build, 116, 263 (2016)

14. A. Jurelionis, L. Stasiuliene, T. Prasauskas, D. Martuzevicius, Indoor and Built Environ, 27(2), 205 (2018)

15. Y. Zhou, Y. Deng, P. Wu, S. J. Cao,. Build Environ, 125, 192 (2017)

16. M. H. Dehghan, M. Abdolzadeh, Build Environ, 133, 161-177 (2018)

17. J. A. Myhren, S. Holmberg, Energy Build, 40(4), 524 (2008)

18. J. A. Myhren, S. Holmberg, Energy Build, 41(1), 92 (2009)

19. K. Horikiri, Y. Yao, J. Yao, Build Environ, 77, 135 (2014)

20. J. A. Myhren, S. Holmberg, In Proceedings of the Healthy Buildings, 2, 47 (2006)

21. H. Ounis, G. Ahmadi, J. B. McLaughlin, J Colloid Interface Sci, 143(1), 266 (1991)

22. L. Talbot, R. K. Cheng, R. W.Schefer, D. R. Willis, J Fluid Mech, 101(4), 737 (1980)

23. A. Li, G. Ahmadi, Aerosol Sci Technol, 16(4), 209 (1992)

24. P. G. T. Saffman, J Fluid Mech, 22(2), 385 (1965) 